\title{
METHODOLOGICAL FOUNDATIONS OF USER INVOLVEMENT RESEARCH: A CONTRIBUTION TO USER-CENTRED DESIGN THEORY
}

\author{
A. Wallisch ${ }^{\otimes}$ and K. Paetzold \\ Bundeswehr University Munich, Germany \\ $\square$ anne.wallisch@unibw.de
}

\section{Abstract}

The concept of involving user perspectives into product development processes has its roots in the early 1960s. Although this seems to be following a quite long tradition, as a design research field, it did not improve substantially and, so far, no consistent perception or even definition of the concept can be found. The paper points out where design research on user involvement still lacks methodological and theoretical foundation and makes the attempt of providing impulses for systemizing the existing body of knowledge within the Design Society as a research community.

Keywords: user-centred design, design methodology, design science, design research, design theory

\section{Introduction}

The role of design as a discipline started with a functional theory for design activities (Bayazit, 2004), more preoccupied with the making an object per se, rather than with its process making nor with the consequences of doing so. The improvements applied to product engineering, the systematization that occurred in the 1940s and 1950s, pushed by the technological enhancement of systems through computational efficiency, increased the need for design research methods to tackle complex issues, and so the perspective on design engineering started to shift in the 1960s. It was, for example, suggested that designers "ought to be asking what systems do, instead of what they are made of, and more so who they are built for" (Rittel and Webber, 1973: 157). Consequently, since now users were starting become key in design decisions and figuring out what their goals and concerns are became a key component to design (Bayazit, 2004). In line with that, in the 1980s, the values of Design were defined as "practicality", "ingenuity", "empathy", and "a concern for 'appropriateness"” (Cross, 1982: 221).

According to Kelley and Kelley (2013: 20), the three core characteristics for evaluating the success of a product or service are feasibility, viability, and desirability, which is defined as being "about deeply understanding human needs, [...] understanding why people do what they do, with the goal of understanding what they might do in the future". Accordingly, in the context of user-centred design (UCD), the perceptions, emotions, expectations and reactions resulting from in the use of a product or service are clearly focused (Ritter et al., 2014). This includes human-centred design for interactive systems being defined as: "Design is based on an explicit understanding of users, tasks and environments, the users are involved throughout design and development and the design is adopted and refined by user-centred evaluation" (ISO, 2019). As there are multiple principles that underlie $\mathrm{UCD}$, it is important to note that the UCD process does not specify exact methods for each design 
phase, which means that the question of how to achieve the required user involvement often stays unanswered. The paper at hand is aimed at addressing this gap by examining the concept of user involvement from a design research perspective. The rich body of literature led to assume that the field is not lacking in knowledge but rather in systematic knowledge organization. Consequently, the paper at hand is not about gathering new insights on the subject but rather about providing impulses for systemizing the knowledge already existing within the Design Society. Therefore, in the next section (2), the research approach followed is outlined, serving as basis for examining the core characteristics of UCD research, which are revealed in section 3. Research methodological thoughts on the results are derived in section 4, resulting in some clues for the concept of user involvement in the following section (5). Eventually, implications for further research are given.

\section{Researching the research landscape of user-centred design}

If technology aims at supporting what people, as users, are trying to do, the people who use technology must be considered as being part of the systems they use. On the one hand, people are diverse, but on the other hand, they also have some characteristics in common. By understanding the characteristics of users, designers and developers are able to create more effective, safer, efficient, acceptable, and enjoyable systems. Alas, just few of these characteristics are directly visible or available to designers and developers without much closer investigation. Designing a user-centred way is about understanding people's patterns of behaviour and predicting when people are likely to do things, and how they choose to do things the way they do them. This is about understanding the options and assessing what resources people actually have or perceive to have, as well as the constraints they are under (Walter et al., 2015). Reflection and experimentation with potential users of the system to be developed should take place throughout the design and development process using methods like brainstorming, storyboarding, low or high fidelity prototyping, and, as the system gets closer to full functionality, more formal use testing (Lee and Coughlin, 2015). This idea follows the approach of involving users in design and development. Even though within the last decades lots of research has been carried out on this concept, it still seems to be rather vague defined. On the other hand, meanwhile, an overload of 'methods of user involvement' seem to exist without conceptual clarity. To the authors, both perceptions seemed quite contradicting. Taken into account the gap of experience and interest between design professionals and academic perspectives on the subject, the initial research objective was aimed at revealing how UCD is perceived and implemented in practice and, thereby, how user involvement is achieved, with which effort, results, and requirements in terms of methodological support. For doing so, an intensive literature review based on SCOPUS was carried out to identify how the field did evolve over time.

What turned out to be, was an analytical blurry state of the art, influenced and fragmented by concepts and terms of various research disciplines. Accordingly, instead of further extending this literature review, it seemed more fruitful to examine some core characteristics of UCD as a research field firstly, in order to gain fundamental clues on how to improve design theory and thereby, how to frame existing results and to develop new research questions based on that. To identify patterns within the blurry field, which can be further analysed for content relations and knowledge gaps, as a starting point, a smaller data basis was needed. Due to the various interdisciplinary influences within the research field, limitation to single disciplines did not seem promising. Assuming that every research community establishes kind of its own language over time, the authors decided on limitation to a single research community instead, and, due to their interdisciplinary scope, chose the Design Society. Still, the data basis was overwhelming. To narrow it down, the investigation period was determined to ten years. Taking into account that the body of literature is growing quickly, two main conferences were chosen as data source, which grounds on the proceedings of the International Conference on Engineering Design (ICED) and the International DESIGN Conference from 2009-2019. Previous studies disclosed the field as operating with very different terms and from a design researcher's point of view, the risk to leave out relevant and valuable approaches and methods in a literature review is quite high (Wallisch et al., 2019). Therefore, four prominent search terms (user-centred, humancentred, user involvement, customer preference) were used to start with. The contributions identified this way were then examined for the neighbouring terms used, which were applied to the search again. 
This procedure was repeated until no new literature was identified, i.e. theoretical saturation could be assumed. Eventually, 1336 papers were identified as being relevant for further in-depth analyses.

\section{Characteristics of user-centred design as a research field}

UCD captures the concept of involving users in the design process of systems by understanding their needs and different contexts in order to derive design requirements. The aim is to design and develop products oriented towards the needs and interests of potential users so these find them useful and usable (Nielsen, 1993). In fact, product desirability goes beyond pure practicality and usability and encompasses its entire user experience (Garrett, 2011). Among all papers analysed here, it is consensual that designers and developers need methodical support in understanding potential users. Primary goals of design approaches and the application of methods are quite diverse, however.

\subsection{Multi-perspective fragmentation}

The need to consider human capabilities and characteristics when designing technologies and systems has long been recognized, as the 50 years old statement that "the need for the future is not so much computer oriented people as for people oriented computers" (Nickerson 1969:178), illustrates. Since then a number of fields have grown up, explicitly concerned with how to design effective technologies and systems that have taken up that call and are concerned with improving how people with them. The intellectual roots of UCD lie in several areas of basic and applied research, including insights from technical- and human-oriented sciences, as for example psychological facts and principles of particular significance for design (Fitts, 1951). Each of these has a slightly different focus and breadth, and each encompasses many different perspectives and methodologies. What all have in common is that they grow their methods and deliverables in response to changes in the technological landscape. Since the focus on effectiveness, efficiency and satisfaction is not seen as being sufficient to meet user needs adequately in product design, the concept of user experience gained attention (Law et al., 2007). User attributes can be involved by following various design approaches focusing on specific aspects of user aspects and behaviour, e.g. "Emotional Design" after Norman (2006).

The analysis resulted in 15 different so-called design approaches, which are ranked and shortly described in the order they had been referred to the most. The sources given were randomly selected as exemplary references to publications based on the individual approaches. Participatory design (Watanabe et al., 2013) or co-design (Jimenez-Narvaez et al., 2015) is an approach to design attempting to actively involve all stakeholders in the design process to help ensure the result meets their needs and is usable. This addresses that gaps in experience and knowledge between designers and users are large when products are developed for people who have a limited role in design and are often reduced to testers in the late design process, which is criticised as being the reason that the needs and expectations of people are not properly assessed in design practice. Universal design (Ki Moon, 2009), inclusive design (Herriott, 2014) or design for all (Gual et al., 2011) aims to open up the broadest possible usability of a product for very different users. If the product design focuses on a specific characteristic of the user group, this can stigmatize the users, therefore, behind the design terms used synonymously lies the claim to extend the design specifications for a product to the needs of restricted groups of people. Following the assumption that design disciplines are effective in studying scientifically the close interactions between people and objects in real and daily life, over the last two decades, interaction design has emerged in order to integrate the different levels of user experience, industrial design and human computer interaction expertise (Kim et al., 2009). Emotional design (Ortíz et al., 2013) strives to create products that elicit appropriate emotions, in order to create a positive experience for the user. To do so, designers consider the connections that can form between users and the objects they use, and the emotions that can arise from them (Stavrakos and AhmedKristensen, 2013). User experience design, which emerged in the field of human computer interaction, also highlights that the emotions a product elicits strongly influence users' perceptions of it (Ariza and Maya, 2014) and should be considered for the user interface design (Graziosi et al., 2013). Closely related to this is user-centred design as defined in the ISO 9241 standard (2019), which differs from UCD as the overarching philosophy of all approaches by a much more concrete focus on usability on an operative level of design (Ottosson and Sterten, 2014). Both perspectives, normative and operative, 
believe that understanding the details of individuals' experience give greater insight than the aggregated reports from market research. Ergonomic design requires an understanding of this variability in human bodies as well as human preferences, and its incorporation into the design process. It is the application of psychological and physiological principles to the engineering and design of products, processes, and systems (Sosa et al., 2018). Behavioural design is concerned with how design can shape, or be used to influence human behaviour (Eigner et al., 2016). All approaches of design for behaviour change acknowledge that artefacts have an important influence on human behaviour and/or behavioural decisions. Kansei design (Shao et al., 2019) aims at the development or improvement of products and services by translating the customer's psychological feelings and needs into the domain of product design (i.e. parameters). The Japanese approach parametrically links the customer's emotional responses (i.e. physical and psychological) to the properties and characteristics of a product or service. In consequence, products can be designed to bring forward the intended feeling. Emphatic design (Morris and Cormican, 2012) or compassionate design (Seshadri and Reid, 2015) aims sensitizing designers and developers to contexts that have high emotional involvement of users.

Overall, partially independent development of similar approaches become apparent in different regions, emphasizing their relevance. These are accompanied by different terminologies, which make it difficult, especially for design novices, to grasp and contextually locate new methods or terms. If they consequently strait on single design approaches or specific user aspects, however, prior experiences could determine the way engineers approach their design task and cause some fixations as far as the problems identified are concerned. Mutual references or even efforts to harmonize the different approaches remain rather limited, which not only hinders proper selection of methods in development practice, but also systematic further development of the entire field of research.

\subsection{Multi-disciplinary terms and concepts}

If designers and developers want to design better technologies and products that are intended for human use, they need to have a good understanding of the people who are or will be using their systems. Understanding people means that designers and developers need to know how to observe and document what people do what for, which is about developing insights into people's conscious and unconscious motivations for doing things (Amman, 2009). This, in turn, is about using appropriate methods to get credible results and differentiate anecdotes from reliable data. The interdisciplinary nature of UCD research results in a plurality of terms and methods. UCD is focusing on the goals of the targeted users instead of what seems to be a good design idea, including implicit user-needs (e.g. usability) and explicit user-requirements (e.g. functions and attributes, see $\mathrm{Hu}$ et al., 2013). Userdriven design decisions or user-oriented designs are described as being based on what users are asking for, which means based on customer's demands (Jordan, 2000). Over the last decades, literature carried out various terms used in user-centred development and design publications. The terms human-, customer-, consumer- and user-oriented, for example, reflect the different roles of and views on the users to be addressed within the work. As discussed in Isa and Liem (2015), for example, the term human-centred design originally expanded the focus from the user in interaction with the system (e.g. a cane) to considering how human capabilities and characteristics are affected by the system beyond direct interaction with the system itself (e.g. a sensorial system). Within the broader sample used for the investigation at hand, these differences seem to became blurred and terms are used synonymously, which some point causes confusion and hinders an improved academic discussion of UCD as a research field. To describe their approach, some of the authors use only one specific term, some only refer to a specific design approach, some use a variety of terms synonymously, and others name no such thing and just use some kind of user-oriented technique. Within this study, the attempt to identify specific usage patterns of different terms and underlying concepts did fail so far, but stated an eclectic use of research terms and concepts. Regarding the use of methods has to be stated that some authors did not explicitly name the methods they used and others describes rather activities related to their interaction with users that, technically, are not considers as methods (e.g. CAD and workshops). Nevertheless, a variety of methods was found, in which, for example, the term interview subsumes different kinds of interview techniques, like semi-structured and expert interviews as well as 
web-based questionnaires, while document analysis encompasses anything from sketches to protocol $\log$ s and technical literature reviews. Diversity among the approaches, activities and their classification by the corresponding researcher is even larger. For example, personas were used and within one single conference (ICED 2017) being referred to as being a method, a design methodology, a theory, a template and a generative tool. Without consistent terminology to describe the user involvement process and classify its activities, research on related work and methodological support remains rather incomplete. The Design Methods Finder (2019) identified 70 methods as being helpful in the context of UCD, and several attempts to classify at least some have been undertaken (e.g. Olsen and Welo, 2011; Zogaj and Bretschneider, 2012). However, because these methods are not as well known in practice as is assumed in science, even a more or less complete collection offers no significant practical benefits without supporting the appropriate selection. It appears designers often cannot tell the differences between the various concepts. The (dis-)advantages of using one method instead of another are not properly discussed, and instead of using the most appropriate method, they tend to use those with which they are already familiar. One possible explanation lies in the interdisciplinary nature of these methods: When designing for people, insights from human and social sciences and their research approaches are needed. Useful interpretation of the results of this application, in turn, requires a corresponding understanding of the underlying concepts of both domains. Confusions of terms or contexts not only prevent insights from being revealed but also might cause misinterpretation and produce research artefacts. According to Sanders and Stappers (2008), interdisciplinary cooperation and teamwork form the basis for effective and efficient user involvement. Fundamental for that is a common design (research) language with a unique and consistent positioning of concepts and terms, however.

\subsection{Multi-level interdependencies}

Usually, designers and developers differ from users in their experiences, life situation, and even language. Therefore, users sometimes have problems to understand what they are looking at. On the one hand, users often cannot use the systems as well as the engineering designers because they do not know as much. On the other hand, sometimes, the opposite is true: users can to be quite resourceful and innovative, and will often use technology in ways that the designer had never fully contemplated. Therefore, the question is not if potential users should be analysed but rather how this has to be done.

Only if designers and developers understand their potential users and take appropriate account of them when designing their system, three main types of benefits or payoffs can result from this analysis: more usable products, which can lead to wider adoption and more accelerated adoption rates, cost savings (Booher and Minninger, 2003), and safer systems (Leveson and Turner, 1993). Alas, although improving a system's usability might save health, money, and lead to product success, usability is neither a necessary nor a sufficient condition for success, nor is it a protection against loss of money or health. Even products being well designed with the user in mind may still not be successful. Most or even all aspects must be right for a product or system to succe ed. Making the usability right does not make the rime to market right, it does not make the price appropriate, and other critical aspects such as reliability or marketing may fail. Moreover, the system has to be acceptable to the users. The interface may be well designed on a local level, but if it clashes too much with existing routines, it can quickly fall to disuse (Baxter et al., 2005). Nevertheless, the lack of usability can be a sufficient reason for failure, which can be prevented by researching users. One main challenge is knowing when one should stop analysing the users and start building the system, which seems to be highly dependent on the types of users involved and the particular design task. If one only talks to colleagues as proxy users to determine usability requirements, for example, there is a large risk that the delivery system will not be acceptable to real end users because they have to use the system within a completely different context. This reflects the importance of applying the bestsuited method the best-suited way to the design task given, what needs some methodological and theoretical groundwork. For UCD practice, if there is no chance to compare different concepts based on consistently used metrics, the potential of selecting the most powerful concept to a given design task is wasted, however. 


\section{Towards a research ontology of user-centred design}

Of course there exist concept definitions in product development literature (e.g. Pahl et al., 2007; ISO, 2019) and the topic of conceptual diversity in design research also has already been addressed (e.g. Blessing and Chakrabarti, 2009; Gericke et al., 2017). However, these terminologies seem incomplete if applied to the context of UCD. Each area of design establishes specific methodologies corresponding its specific conditions of practical application, which requires specific methods and tools. If new areas of design emerge, new terms and concepts are required to describe the new subject precisely. Only if all terms and concepts used in a specific design context are well reflected in such terminology, it provides support for design practice. Wallisch et al. (2019) did a comprehensive literature review in the field of user involvement and collected all research terms having been used. After looking up the interdisciplinary definitions and integrating them to the list, they came up with a terminology of the concepts used within the field, which allows a consistent positioning of all terms relevant for communicating on the subject of UCD by the broadest audience. This is fruitful because the point of involving users into the design process is lost without being able to define it, classify it and define its boundaries. If metrics cannot be derived, validation cannot be achieved satisfactorily. If there is no clear and common understanding of the research concepts, methods can hardly be transferred into design practice and the improvement of methods and processes is left to chance. To limit the confusion over the definitions and methods is the first necessary step to turn out the value of user involvement. On the other hand, it is questionable to what extend it makes sense to find the battle for narrow definitions. If most terms and concepts were used interchangeably, does it serves practicalities to follow a classification based on all subtle differences or is it more fruitful to focus on the common core elements of the concepts? Considering that defining the class of methods needed for involving users in design activities has to be done before weighing their variations and causalities, here the authors decided to not going into detail too soon. The aim was to provide a classification scheme, in which the concepts, terms and methods identified during the analyses phase can be sorted. By doing so, research gaps, double research, and analytical weakness of concept descriptions can be identified easily. In addition, a basis for comparison emerges: So far it has been observed that activities, methods and methodologies are crossed with each other in order to derive the success of a measure. This does not allow reliable statements, however. Therefore, the terminology provided by Wallisch et al. (2019) was validated in terms of relevance to the sample and condensed on five analytical levels, which are more generic on the top and getting more and more specific in the following (Figure 1):

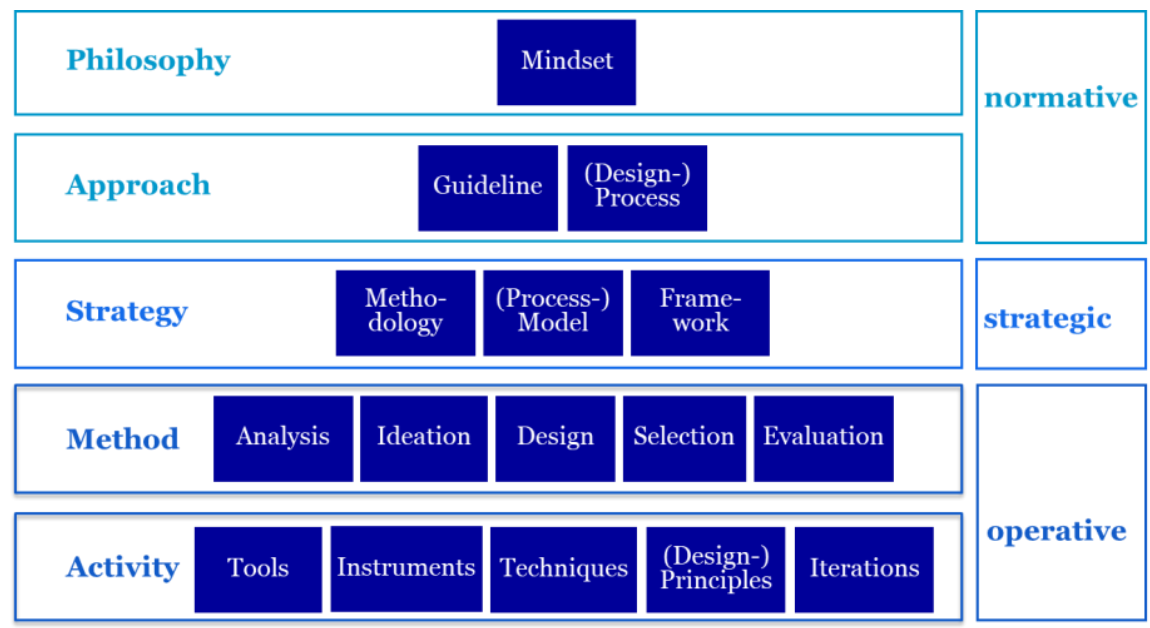

Figure 1. UCD-related research ontology

Based on Rügg-Stürm (2005), design decisions are of normative, strategic or operative reach, reflecting the organizational level UCD activities have to be grounded in order to provide the resources required for successfully carrying out these activities. The philosophy describes humancentring as the overriding mindset of all product development activities. On the level of the approach, design concepts with their own philosophies on how to develop products that are as user-centred (and 
thus successful) as possible, for example by focusing on user motives, on the emotions that a user develops in relation to a product, and which influence the purchase or usage decision, are described. On the strategy level, the framework conditions for implementing the design (research) process in the company and the resources provided or required are subsumed. This can only be the case if the development philosophy of the company agrees with its strategy. Whereas methods are intended to support individual development activities, methodologies aim at supporting overarching strategic objectives, which can only be achieved by the corresponding nexus of goal-oriented activities. On the level of methods, due to their multitude, further structuring into method classes corresponding to specific goals (e.g. analysis, ideation, evaluation, and so on) is recommended. Here too becomes apparent why simple method collections offer limited value for practice: if the corresponding mindset is missing within the company, the resources to select the best possible method are probably also lacking. Activities are ultimately the application of methods with the help of certain techniques, tools and design principles (e.g. of Universal Design, see Conell et al., 1997. Other design philosophies, as e.g. agile development, are based on value principles, playing a role in determining the development framework. This too reflects the context dependency of concepts that might cause mismanagement of design activities, if not considered).

The scope of this ontology can be summarized in such a way that not all identified concepts are necessarily used in each development project. Furthermore, within each conceptual level, a ranking of the contained concepts does not seem beneficial because wording is established company-specific mostly and it would not be expedient in practice to put this in question. It is more important to be aware of their classification on the operative, strategic and normative level, and thus of the boundary conditions and the scope of the design decisions resulting from them. Since concepts, their contents and the associated conclusions for the application of methods and procedures are perceived differently in various contexts, conceptual ambiguities, if not being well reflected, can hinder efficiency and effectiveness of the design process in its corresponding decisions. Its context-specific adaption is of vital importance for the goal-oriented selection and application of methods. In the field of user-centred engineering and design different design approaches focus on different facets to help designers to increase their empathy for and understanding of users. Here, the example of user involvement as design approach is chosen to illustrate the UCD-specific application of the research ontology presented above (see Figure 2). The approaches discussed earlier (3.1.) provide similar logical sequences.

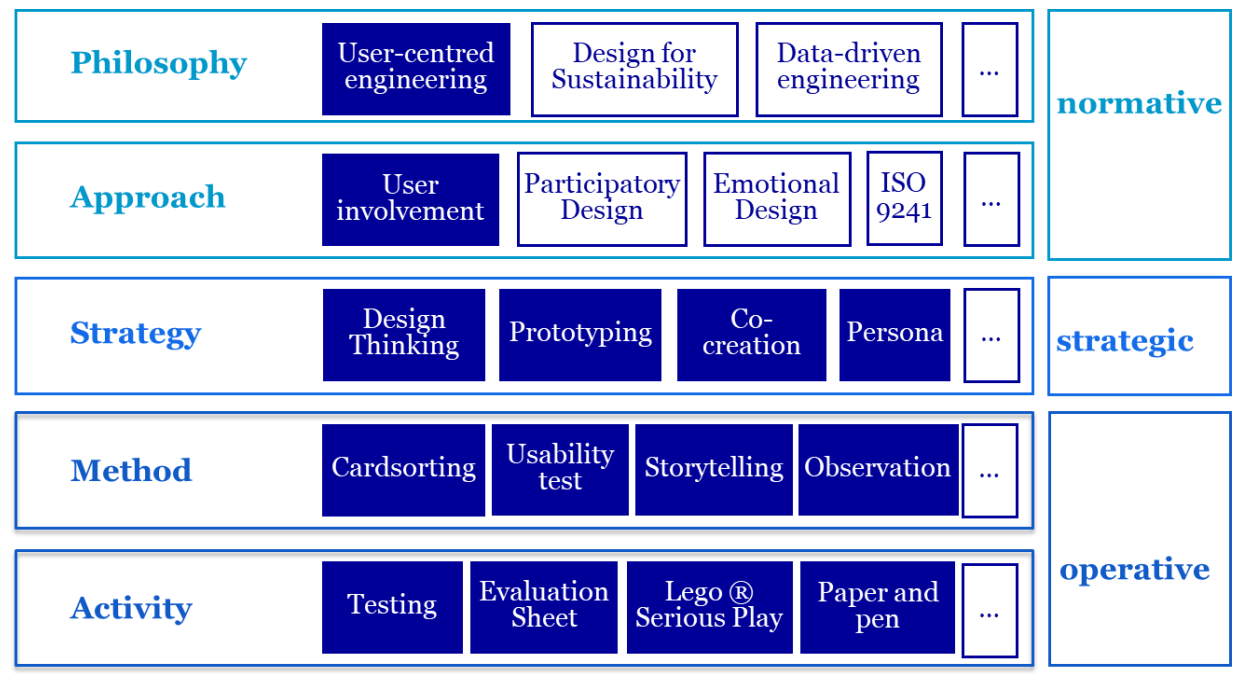

Figure 2. UCD-specific application

User involvement can be participatory throughout, e.g. through co-creation, or through persona that replace the presence of a user. Design strategies like this determine the methods to be used. For example for the design task given, in various phases, storytelling, observation, card sorting and usability tests might serve best. Finally, these, reflecting the resources given, determine what has to be done on an operative level, e.g. use paper and pen, rank different options, and so on. Following this logic, it is possible to distinct the different concepts being summarized improperly as 'methods of user 
involvement' in order to make them a bit more comparable. Potentially, this facilitates the extraction, description, comparison and assessment of methods to involve users in design and development.

\section{The concept of user involvement}

The analysis showed that user involvement is a possible approach to developing a product geared to user needs. In terms of content, for example, the concept differs from the participatory approach in the open degree of participation. Involving users can also be understood as a strategy to realize other design approaches (e.g. user experience design). However, even at this level nothing yet is said about the concrete implementation of the involvement. Consequently, user involvement (or -integration) is not to be classified as a method, as stated by some authors, because the concept does not come along with a description of a rule-based and planned procedure to achieve a certain objective, i.e. design activity.

On the method level, it can be seen that developers and designers receive comparatively much support in collecting and understanding user requirements, with comparatively little design support. Multitudes of suitable methods for user description are available from the human-oriented disciplines already. Their strict assignment to the phases of the product development process does not seem too fruitful because of the different research logic of these methods. Each can be used in various phases to form decisions, but so far, there is no systematic support for these decisions. A genuinely user-centred development method could not be found within the scope of the study. The user is to be integrated into previous development activities. However, this changes the processes and activities, so the development methods must also be adapted. Strictly speaking, the participating user provides information that the designer translates into a design decision. He is the one who decides, the user has to validate the consequences of this decision again on their suitability in his sense. Design support is needed in terms of the appropriate synthesis of user research results into design and development activities, which means the translation of user requirements into product specifications. Need for support also appears in terms of design and selection methods, as these are, compared to methods for gathering user data, not well represented in the sample. In addition, the processual aspects of user involvement in design and development activities should gain more attention.

\section{Critical reflection and implications for further research}

Despite its history, as a design research field, UCD and the approach of involving user perspectives into development activities did not improve substantially. Literature contains numerous explanations of the terms, but there is no consistent perception or even generally acknowledged, concise definition. Presumably, such definition will never exist, but as with the term user experience, there will be a largely agreed understanding, still leaving room for different emphases. By analysing a rich body of literature, published within the Design Society, the paper points out where design research still lacks methodological and theoretical foundation and, consequently, design practice lacks design support for involving users into development and design activities. On the one hand, the authors identified a need in methods to support the situation-specific selection and adaptation of existing methods rather than in new methods aimed at understanding users. In order to support the selection of methods fostering specific UCD activities, these methods need to be comparable under certain views, which reflects the need for their classification. The composition of method classifications is challenging, especially when this classification should be suitable multidisciplinary. The analysis revealed ambiguity towards not only methods but also several terms and concepts related to user involvement. Spot-like comparisons with literature published within other research communities (found in SCOPUS) point to a certain degree of generalizability but, since the sample is limited to two sources and one decade of publishing, this has to be further investigated. To clean up this fuzziness, a research ontology was condensed proven reliable when applied to the UCD context. Further research needs to be pursued to empirically validate its benefit in UCD practice. On the other hand, the authors revealed that once the user data is gathered, methodological support in terms of transforming qualitative user insights in technical requirements is needed. Even if engineering designers are carrying out extensive user research, there is usually this one point in the development process, at which technical parameters become more important to them than the user's input. Further research on understanding the conditions based on which design practitioners 
make their decisions is needed, in order to formalize these translation processes for education. Beyond that, it might be fruitful to structure the literature found on whether they thematise normative, strategic and operational aspects, in order to summarize the history and evolution on UCD and to condense central arguments and trends, on which UCD theory can be grounded.

\section{References}

Amman, E.M. (2009), “The Knowledge Cube and Knowledge Conversions”, World Congress on Engineering 2009 Vol I, WCE 2009, 1-3 July 2009, London, U.K., pp. 1-6.

Ariza, N. and Maya, J. (2014), "Proposal to identify the essential elements to construct a user experience model with the product using the thematic analysis technique", 13th International Design Conference (DESIGN 2014), Dubrovnik, Croatia, pp. 11-22.

Baxter, G.D. et al. (2005), "Using cognitive task analysis to facilitate the integration of decision support systems into the neonatal intensive care unit", Artificial Intelligence in Medicine, Vol. 35 No. 1, pp. 243-257.

Bayazit, N. (2004), "Investigating design: A review of forty years of design research", Design Issues, Vol. 20 No. 1, pp. 16-29.

Blessing, L.T.M. and Chakrabarti, A. (2009), DRM, a Design Research Methodology, Springer, London.

Booher, H.R. and Minninger, J. (2003), "Human systems integration in army systems acquisition", In: Booher, H.R. (Ed.), Handbook of human systems integration, John Wiley, Hoboken, NJ, pp. 663-698.

Cross, N. (1982), "Designerly ways of knowing”, Design Studies, Vol. 3 No. 4, pp. 221-227.

Conell, B.R. et al. (1997), The principles of universal design. [online] NC State University. The Center for Universal Design. Available at: https://projects.ncsu.edu/ncsu/design/cud/about_ud/udprinciplestext.htm (28.12.2019).

Design Methods Finder (2019), Design Methods FTW! [online] Design Methods Finder. Available at: https://designmethodsfinder.com (14.10.2019).

Eigner, M., Dickopf, T. and Huwig, C. (2016), "An interdisciplinary model-based design approach for developing cybertronic systems”, International Design Conference (DESIGN 2016), May 16-19, 2016, Dubrovnik, Croatia, pp. 1647-1656.

Fitts, P.M. (1951), “Engineering Psychology and Equipment Design”, In, Stevens S.S. (Ed.), Handbook of experimental psychology, John Wiley, New York, pp. 1287-1340.

Garrett, J.J. (2011), The Elements of User Experience: User-Centered Design for the Web and Beyond, Second Edition, New Riders, Pearson Education, Berkeley.

Gericke, K., Eckert, C. and Stacey, M. (2017), "What do we need to say about a design method?", 21st International Conference on Engineering Design (ICED 17), Vancouver, Canada, 21-25 August 2017, pp. 102-110.

Graziosi, S. et al. (2013), “A method for capturing and translating qualitative user experience into design specifications: the haptic feedback of appliance interfaces”, 19th International Conference on Engineering Design (ICED13), 19-22 August 2013, Seoul, Korea, pp. 427-436.

Gual, J., Puyuelo, M. and Lloveras, J. (2011), "Universal design and visual impairment: Tactile products for heritage access", International Conference on Engineering Design (ICED11), 15-18 August 2011, Lyngby/Copenhagen, Denmark, pp. 70-80.

Herriott, R. (2014), "Delimiting Inclusive Design", 13th International Design Conference (DESIGN 2014), Dubrovnik, Croatia, pp. 2051-2060.

$\mathrm{Hu}$, F. et al. (2013), "Semiotic Basis for designing Product Architecture", International Conference on Engineering Design, ICED13, 19-22 August 2013, Seoul, Korea, pp. 159-168.

Isa, S.S. and Liem, A. (2015), "A comparative study on the role of models and prototypes in human-centered design versus design-driven innovation approaches", International Conference on Engineering Design, ICED2015, 27-30 July 2015, Politecnico di Milano, Italy, pp. 203-214.

ISO (2019), "ISO 9241-210:2019: Ergonomics of human-system interaction - Part 210: Human-centred design for interactive systems", International Organization for Standardization, Geneva.

Jimenez-Narvaez, L.M. et al. (2015), "Harnessing social media and cloud-computing technologies for co-design in open collaborative innovation: The case of 24 hours of innovation", 20th International Conference on Engineering Design (ICED 15), 27-39 July 2015, Milan, Italy, pp. 207-216.

Jordan, P.W. (2000), Designing Pleasurable Products, Taylor \& Francis, London.

Kelley, T. and Kelley, D. (2013), Creative Confidence: Unleashing the Creative Potential within Us All, HarperCollins UK, London.

Ki Moon, S. (2009), "Universal product platform and family design for uncertain market", 17th International Conference on Engineering Design, 24.-27 August 2009, Palo Alto, CA, USA, pp. 59-70. 
Kim, Y.S., Lim, J.S. and Park, J.A. (2009), “Affordance Feature Reasoning: a Case Study for Human-Product Interaction”, 17th International Conference on Engineering Design, 24-27 August 2009, Palo Alto, CA, USA, pp. 429-440.

Law, E. et al. (2007), Towards a UX Manifesto, COST294-MAUSE affiliated workshop, Lancaster, UK.

Lee, C. and Coughlin, J.F. (2015), "User involvement in product design practices: A case study on technologies for older adults", 20th International Conference on Engineering Design (ICED 15), 27-39 July 2015, Milan, Italy, pp. 33-44.

Leveson, N.G. and Turner, C.S. (1993), “An investigation of the Therac-25 accidents”, IEEE Computer, Vol. 26 No. 7, pp. 18-41.

Morris, S. and Cormican, K. (2012), "Towards empathic design in the Irish medical device industry", 12th International Design Conference (Design 2012), Dubrovnik, Croatia, pp. 1039-1048.

Nickerson, R. (1969), "Man-Computer interaction: A challenge for human factors research", IEEE Transactions on Man-Machine Systems, Vol. 10 No. 4, pp. 164-180.

Nielsen, J. (1993), Usability engineering, AP Professional Press, Chestnut Hill.

Norman, A.D. (2006), Emotional Design: Why we love (or hate) everyday things, Basis Books, New York, NY.

Olson, T.O. and Welo, O. (2011), "Maximizing Product Innovation through Adaptive Application of UserCentered Methods for Defining Customer Value", Journal of Technology Management \& Innovation, Vol. 6 No. 4, pp. 172-192. https://dx.doi.org/10.4067/S0718-27242011000400013

Ortíz Nicolás, J.C., Aurisicchio, M. and Desmet, P.M.A. (2013), "Differentiating positive emotions elicited by products: an exploration of perceived differences between 25 positive emotions by users and designers", 19th International Conference on Engineering Design (ICED13), 19-22 August 2013, Seoul, Korea, pp. 247-256.

Ottosson, S. and Sterten, J. (2014), "User participation is not always an easy thing when developing an innovation", 13th International Design Conference (DESIGN 2014), Dubrovnik, Croatia, pp. 579-588.

Pahl, G. et al. (2007), Engineering Design: A Systematic Approach, Springer Verlag, London.

Rittel, H.W.J. and Webber, M.M. (1973), "Dilemmas in a general theory of planning", Policy Sciences, Vol. 4 No. 2, pp. 155-169.

Ritter, F.E., Baxter, G.D. and Churchill, E.F. (2014), Foundations for Designing User-Centered Systems: What System Designers Need to Know about People, Springer, London. https://dx.doi.org/10.1007/9781447151340

Rügg-Stürm, J. (2005), The New St. Gallen Management Model: Basic Categories of an Approach to Integrated Management, Palgrave Macmillan, UK, https://dx.doi.org/10.1057/9780230505162.

Sanders, E.B.-N. and Stappers, P.J. (2008), "Co-creation and the new landscapes of design", Co-Design, Vol. 4, No. 1, pp. 5-18.

Seshadri, P. and Reid, T. (2015), "Novice Engineers' predisposition to compassionate design", 20th International Conference on Engineering Design (ICED 15), 27-39 July 2015, Milan, Italy, pp. 143-152.

Shao, D., Nagai, Y. and Sosa, R. (2019), "Design for sustainability and innovation: a kansei engineering evaluation of the adaptive reuse of old buildings”, International Conference on Engineering Design (ICED19), 5-8 August 2019, Delft, The Netherlands, pp. 3221-3230.

Sosa, R. et al. (2018), "Robot ergonomics: towards human-centred and robot-inclusive design”, 15th International Design Conference (Design 2018), Dubrovnik, Croatia, pp. 2323-2334.

Stravrakos, K.S. and Ahmed-Kristensen, S. (2013), "Investigating the role of aesthetics for interaction design", 19th International Conference on Engineering Design (ICED13), 19-22 August 2013, Seoul, Korea, pp. 557-566.

Wallisch, A. et al. (2019), “Overcoming fuzzy design practice: revealing potentials of user-centered design research and methodological concepts related to user involvement", IEEE International Conference on Engineering, technology and Innovation (ICE/ITMC), 17-19 June 2019, Valbonne Sophia-Antipolis, France. https://dx.doi.org/10.1109/ICE.2019.8792591

Walter, J., Paetzold K. and Nitsch, V. (2015), "Description of a competence orined approach for designing technical assistance systems", 20th International Conference on Engineering Design (ICED 15), 27-39 July 2015, Milan, Italy, pp. 57-64.

Watanabe, K. et al. (2013), “A unified approach for systematic and participatory design”, 19th International Conference on Engineering Design (ICED13), 19-22 August 2013, Seoul, Korea, pp. 191-200.

Zogaj, S. and Bretschneider, U. (2012), "Customer integration in new product development: a literature review concerning the appropriateness of different customer integration methods to attain customer knowledge", [online] SSRN Electronic Journal. Available at. https://dx.doi.org/10.2139/ssrn.2485240 (18.10.2019). 